\title{
Evidence of more efficient whistler-mode transmission during periods of increased magnetic activity
}

\author{
N. R. Thomson ${ }^{1}$, M. A. Clilverd ${ }^{2}$, A. J. Smith ${ }^{2}$ \\ ${ }^{1}$ Department of Physics, University of Otago, Dunedin, New Zealand \\ 2 British Antarctic Survey (NERC), Madingley Road, Cambridge CB3 0ET, UK
}

Received: 10 October 1996 / Revised: 4 March 1997 / Accepted: 6 March 1997

\begin{abstract}
In a previous study it was reported that whistler- mode signals received at Faraday, Antarctica $\left(65^{\circ} \mathrm{S}, 64^{\circ} \mathrm{W}\right)$ and Dunedin, New Zealand $\left(46^{\circ} \mathrm{S}, 171^{\circ} \mathrm{E}\right)$ with entry regions in Pacific longitudes (typically from the VLF transmitter NLK, Seattle, USA) showed an increase in transmission of wave energy as magnetic activity increased. However, signals with entry regions in Atlantic longitudes (typically from the NSS transmitter, Annapolis, USA) did not appear to show such a relationship. This paper reports the results of a study of the same two longitude ranges but with the opposite transmitter providing additional whistler-mode signal information, with $L$-values in the range 1.8-2.6. Transmissions from NLK once again indicate a relationship between the transmission of wave energy and magnetic activity even though the signals were propagating in Atlantic longitudes, not Pacific. Any trend in NSS events observed at Dunedin was obscured by a limited range of magnetic activity, and duct exit regions so close to the receiver that small-scale excitation effects appeared to be occurring. However, by combining data from both longitudes, i.e Pacific and Atlantic, and using only ducts with exit regions that were $>500 \mathrm{~km}$ from the receiver, NSS events were found to show the same trend as NLK events. No significant longitude-dependent or transmitter-dependent variations in duct efficiency could be detected. Duct efficiency increases by a factor of about 30 with $K_{\mathrm{p}}=2-8$ and this result is discussed in terms of changes in wave-particle interactions and duct size.
\end{abstract}

Correspondence to: N. R. Thomson

This article was processed using Springer-Verlag $\mathrm{T}_{\mathrm{E}} \mathrm{X}$ ann geo-macro package 1.0 and the AMS fonts, developed by the American Mathematical Society.

\section{Introduction}

Clilverd et al. (1996) reported the first observed occurrence of simultaneous common-duct whistlermode VLF signals at Dunedin, New Zealand $\left(46^{\circ} \mathrm{S}, 171^{\circ} \mathrm{E}\right)$ and Faraday, Antarctica $\left(65^{\circ} \mathrm{S}, 64^{\circ} \mathrm{W}\right)$, some $7 \mathrm{Mm}$ apart. The signals which came from VLF transmitters situated in North America and propagated along field lines near $L=2.2$ (Clilverd et al., 1992a) were observed between 1992-1994. The locations of the duct exit regions were determined and a subionospheric propagation model was used to estimate signal input and output powers. Two apparent groups of events were reported. One group was described as the 'Atlantic' group and was characterised by ducts with entry longitudes near Faraday conjugate $\left(65^{\circ}-85^{\circ} \mathrm{W}\right)$ with whistler-mode signals originating from NSS. The other group was described as the 'Pacific' group and was characterised by ducts with entry longitudes near NLK $\left(120^{\circ}-140^{\circ} \mathrm{W}\right)$ and whistler-mode signals originating from NLK. The extremes in wave energy transmission efficiency coincided with extremes in magnetic activity, i.e. the lowest efficiency duct occurred after the lowest magnetic activity. Both of the extreme values came from the Pacific data and a logarithmic relationship of increasing efficiency with increasing magnetic disturbance was apparent. This is consistent with the energetic plasma flux and anisotropy increasing with magnetic disturbance (Tanaka et al., 1989). No explanation was proposed for the reason why a similar relationship could not be observed in the events that occurred at Atlantic longitudes.

This paper reports a study of whistler-mode signals, with $L$-values between 1.8 and 2.6, which have propagated in the same longitude ranges as the previous work, but originating from the opposite transmitters (i.e NLK at Atlantic longitudes and NSS at Pacific longitudes). Hence this study allows the elimination of both a longitude and a transmitter effect in the relationship 
between wave-energy transmission efficiency and magnetic activity. The data were collected during 1993-1994 at Dunedin, New Zealand and Faraday, Antarctica.

\section{Experimental method}

The VLF Doppler experiments at Dunedin and Faraday can receive ducted whistler-mode signals from US Navy transmitters (NSS, $21.4 \mathrm{kHz}, 400 \mathrm{~kW}$ at Annapolis, Maryland, and NLK, $24.8 \mathrm{kHz}, 250 \mathrm{~kW}$ at Seattle, Washington). Narrowband receivers of the type described by N. R. Thomson (1981) are able to separate the whistler-mode signals from the stronger sub-ionospheric signal, and measure the group delays $\left(t_{q}\right)$, Doppler shifts, and arrival bearings of the whistlermode component. Results from these experiments have been published by Smith et al., (1987), Saxton and Smith (1989), and Clilverd et al., (1992a,b).

The method of determining the group delays, $L$-shells and propagation paths of the whistler-mode signals is discussed in detail by Smith and Clilverd (1991) and Clilverd et al., (1991). The arrival bearings of the whistler-mode signals are determined from the relative strengths of the signals in two orthogonal vertical loops at each site, together with phase comparisons with the signal received by a vertical electric dipole antenna (Thomson, N. R., 1985; Strangeways and Thomson, 1986).

The VLF Doppler receivers are calibrated by applying artificial signals with known intensities in the range $0.1-1.0 \mathrm{pT}$ and comparing the resultant output with software-generated signals which are recorded in all data files. The calibration signals are generated by applying a known signal to a calibration coil located in the centre of the vertical loops, a technique that is described by Smith (1995). Thus, by comparing the real whistlermode signal strength with the software calibration signal, it is possible to estimate the absolute field strength of the real signal. Hence it is possible to determine the amplitudes of each whistler-mode signal received at either site. The results are given in Table 1 . Typically the faint signals received from distant duct exit regions have signal strengths in the order of $0.5 \mu \mathrm{Vm}^{-1}$, which is near the lower limit of sensitivity of the VLF Doppler system. Strong signals which have short subionospheric paths to and from the duct have signal strengths of up to $70 \mu \mathrm{Vm}^{-1}$, and are comparable with the sub-ionospheric signal strength (typically $200 \mu \mathrm{Vm}^{-1}$ from NSS at night at Faraday).

For the data under study in this paper, the whistler-mode signals from NSS (nearly conjugate to Faraday) received at Dunedin have propagated $\approx 6 \mathrm{Mm}$ subionospherically to the west before entering ducts near to the conjugate point of the receiver. Whistlermode signals received at Faraday from NLK have propagated $\approx 4 \mathrm{Mm}$ sub-ionospherically to the east before entering ducts near to the conjugate point of the receiver. Hence the study involves a transmitter close to the Pacific producing whistler-mode signals at Atlantic longitudes and vice versa.

\section{Results}

Table 1 shows the events where whistler-mode signals from two transmitters have been observed at one receiving site, either Faraday or Dunedin. The positions of the exit regions were located accurately by comparing the group delay times and arrival bearings. The duct entry locations have been determined by IGRF field-line mapping from the exit locations. These duct entry and exit locations are shown in the map in Fig. 1 together with the transmitter and receiver positions. The entry regions of the ducts are consistent with the existence of preferred paths of propagation from transmitter to nonconjugate receiver, given that NLK's latitude is too high for direct entry (Allcock and McNeill, 1966; Clilverd
Table 1. The dates of occurrence of whistler-mode signals and the transmitter they originated from. The maximum value of 3-hourly $K_{\mathrm{p}}$ during the preceding $48 \mathrm{~h}$ is given. $P_{\mathrm{SI}}$ and $E_{\text {in }}$ are determined using LWPC and the received whistler-mode signal amplitude (W-m). The duct efficiency $(\eta)$ is a simple ratio of duct output/input values (see Sect. 4). The upper section of the table shows events based on signals from the NSS transmitter while the lower section shows events from NLK

\begin{tabular}{|c|c|c|c|c|c|c|c|c|}
\hline \multirow[t]{2}{*}{ Date } & \multirow[t]{2}{*}{$K_{\mathrm{p}}$} & \multicolumn{7}{|c|}{ NSS-DUNEDIN } \\
\hline & & $\begin{array}{l}\mathrm{W}-\mathrm{m} \\
\mu \mathrm{Vm}^{-1}\end{array}$ & $\begin{array}{l}P_{\mathrm{SI}}(\mathrm{mW}) \\
\text { NSS }\end{array}$ & $L$ & $\begin{array}{l}\text { Ent } \\
\text { Lat }\end{array}$ & Long $^{\circ}$ & $\begin{array}{l}E_{\text {in }} \\
\left(\mathrm{m} \mathrm{Vm}^{-1}\right)\end{array}$ & $\eta$ \\
\hline 11 Dec 93 & $3_{+}$ & 0.60 & 0.54 & 2.25 & 50 & -160 & 0.35 & 0.46 \\
\hline 02 Apr 94 & 4 & 0.72 & 0.99 & 2.13 & 49 & -160 & 0.63 & 0.50 \\
\hline 11 Sep 94 & $5_{+}$ & 0.48 & 0.99 & 2.07 & 48 & -160 & 0.66 & 0.46 \\
\hline 12 Sep 94 & $4_{+}$ & 0.45 & 1.20 & 1.79 & 44 & -159 & 0.73 & 0.44 \\
\hline 10 Oct 94 & $4_{0}$ & 0.53 & 1.29 & 2.10 & 48 & -158 & 0.59 & 0.74 \\
\hline \multirow[t]{2}{*}{ Date } & \multirow[t]{2}{*}{$K_{\mathrm{p}}$} & \multicolumn{7}{|c|}{ NLK-FARADAY } \\
\hline & & $\begin{array}{l}\mathrm{W}-\mathrm{m} \\
\mu \mathrm{Vm}^{-1}\end{array}$ & $\begin{array}{l}P_{\mathrm{SI}}(\mathrm{mW}) \\
\text { NLK }\end{array}$ & $L$ & $\begin{array}{l}\text { Ent } \\
\text { Lat }^{\circ}\end{array}$ & Long $^{\circ}$ & $\begin{array}{l}E_{\text {in }} \\
\left(\mathrm{m} \mathrm{Vm}^{-1}\right)\end{array}$ & $\eta$ \\
\hline $20 \mathrm{Jul} 93$ & $2_{0}$ & 0.87 & 0.2 & 2.40 & 38 & -70 & 0.63 & 0.20 \\
\hline 14 Sep 93 & $8_{-}$ & 1.5 & 3.3 & 2.57 & 40 & -73 & 0.72 & 2.55 \\
\hline 15 Sep 93 & $8_{-}$ & 1.24 & 3.2 & 2.19 & 35 & -74 & 0.62 & 3.44 \\
\hline 23 Feb 94 & $8_{-}$ & 1.16 & 3.2 & 2.44 & 38 & -75 & 0.71 & 2.54 \\
\hline 17 Apr 94 & $8+$ & 0.85 & 5.5 & 1.96 & 31 & -77 & 1.11 & 1.80 \\
\hline 11 May 94 & $5_{+}$ & 1.0 & 1 & 2.32 & 37 & -73 & 0.6 & 1.11 \\
\hline
\end{tabular}




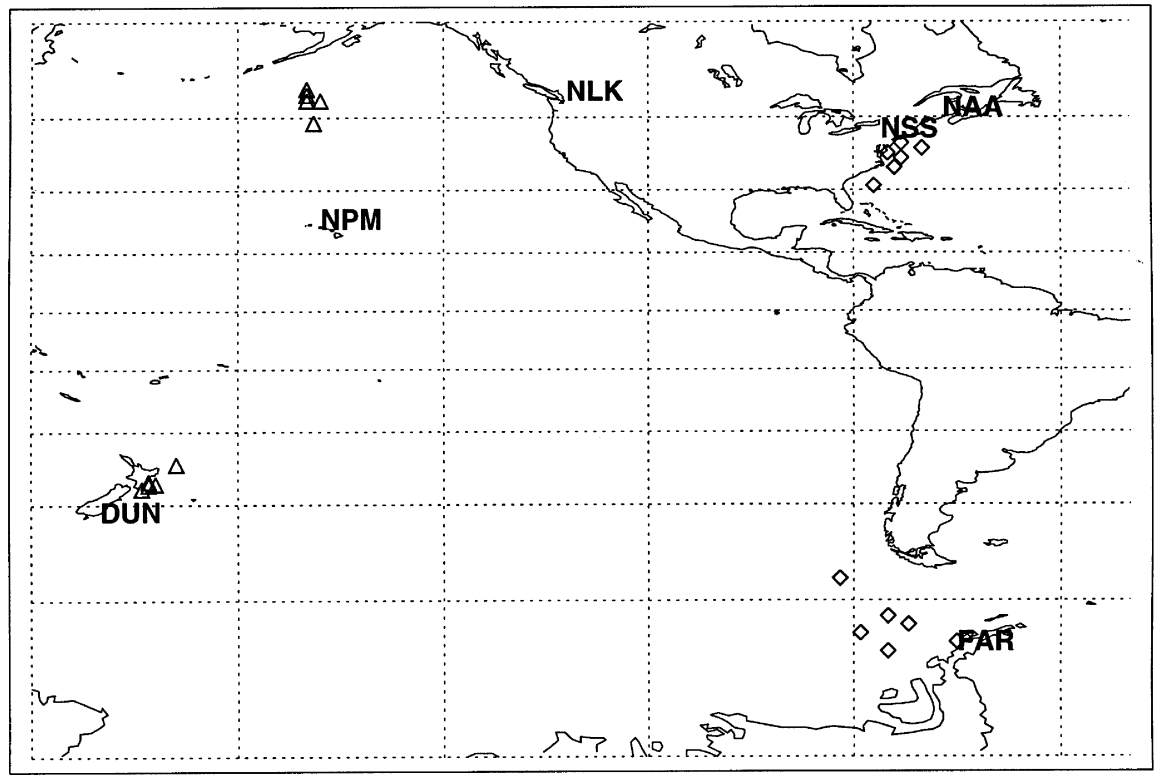

Fig. 1. A map of the locations of the ducts determined from the simultaneous whistler-mode examples. In the northern hemisphere the locations of $4 \mathrm{VLF}$ transmitters are shown (NSS, NAA, NLK, NPM), while in the southern hemisphere the locations of the two receiving sites are indicated (FAR, DUN). Each $\triangle$ represents the entry or exit location of a duct carrying NSS whistler-mode signals, and each $\diamond$ represents the same for NLK signals

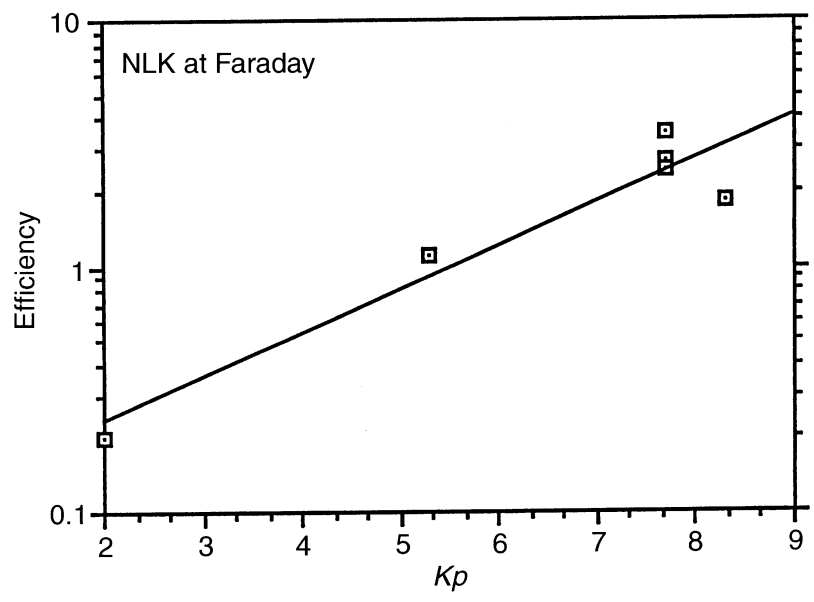

Fig. 2. A plot of the efficiency of ducts determined from whistlermode signals from NLK received at Faraday versus the maximum $K_{\mathrm{p}}$ in the preceeding 2 days

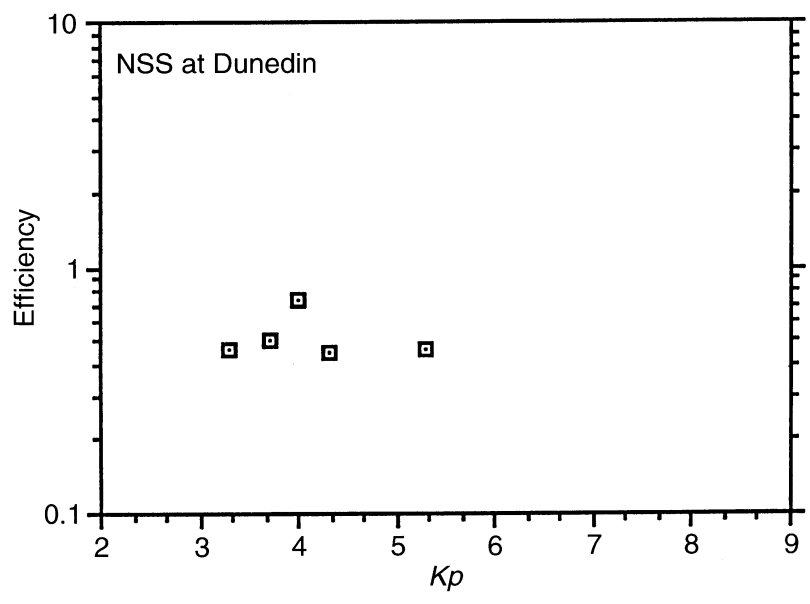

Fig. 3. As Fig. 2, but for NSS signals received at Dunedin et al., 1992a). Table 1 also shows the maximum $K_{\mathrm{p}}$ of the preceding 2 days for each example.

The approximate calculated exit powers $\left(P_{\mathrm{SI}}\right)$ from the measured whistler-mode field strengths at Dunedin or Faraday are shown in column 4. LWPC (Ferguson and Snyder, 1990) was used to calculate the field strength from both a short vertical dipole and a short horizontal dipole (perpendicular to the propagation direction). Clilverd et al. (1996) provide more information on the technique used. The input field strength at the duct entry region $E_{\text {in }}$ was also calculated. Given these values, an estimate of the efficiency of the duct $(\eta)$, including ionospheric losses, can be estimated. Column 9 of Table 1 shows such an estimate. The value simply calculated by using $P_{\text {out }} / E_{\text {in }}^{2}$, where $P_{\text {out }}$ is the power transmitted in the duct. To account for differences in ionospheric penetration and absorption with direction of propagation, $P_{\text {out }}$ was reduced by $3 \mathrm{~dB}$ and $6 \mathrm{~dB}$, respectively, to get $P_{\mathrm{SI}}$ (the output power radiated into the Earth-ionosphere waveguide) for Dunedin and Faraday (Tsuruda, 1973).

Figure 2 shows a plot of the efficiency of NLK events received at Faraday versus the maximum value of $K_{\mathrm{p}}$ in the preceding $48 \mathrm{~h}$ using the data presented in Table 1 . A least-squares fitted line is superposed on the data points and shows that there is a trend of increasing efficiency with magnetic activity. The characteristics of the fitted line are very similar to that found for NLK events at Dunedin in Clilverd et al. (1996). Typically, NLK events studied at both Pacific and Atlantic longitudes have efficiencies of 0.1 when $K_{\mathrm{p}}=2$, and 3 when $K_{\mathrm{p}}=8$.

Figure 3 shows a similar plot to Fig. 2 but for NSS events at Dunedin. No obvious trend is seen in the data and the range of $K_{\mathrm{p}}$ is small. However, the efficiency value for $K_{\mathrm{p}}=5$ is similar to that in Fig. 2 and also for NLK events at Dunedin in Clilverd et al. (1996). 


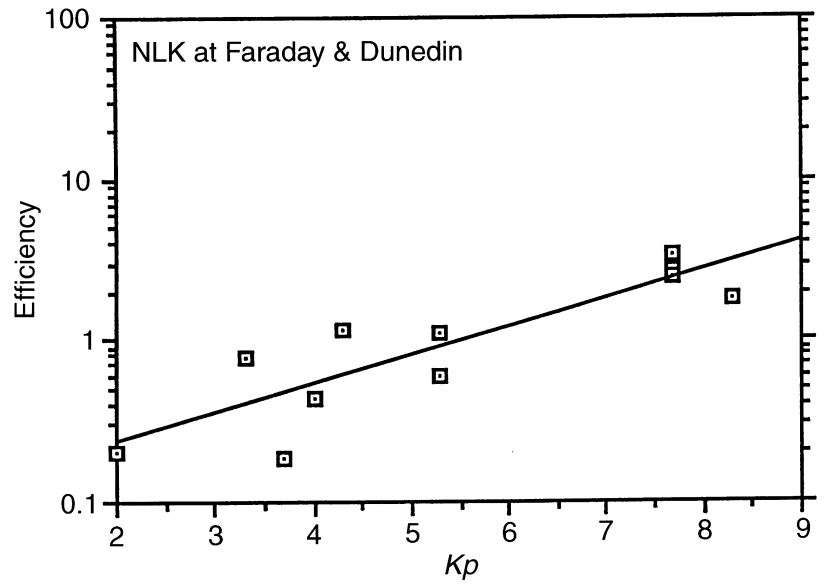

Fig. 4. As Fig. 3, but with NLK events from both Faraday and Dunedin in order to give a greater range of $K_{\mathrm{p}}$ values

\section{Discussion}

Clilverd et al. (1996) found that Pacific ducts showed an increase in efficiency as $K_{\mathrm{p}}$ increased, whereas no such trend could be seen for Atlantic ducts. They posed the question of either longitude variation or transmitter dependence in efficiency. The results shown in Fig. 2 together with Clilverd et al. (1996) indicate that the same variation in duct efficiency is seen in the Pacific and Atlantic longitudes when NLK whistler-mode signals are studied. The results shown in Fig. 3 together with Clilverd et al. (1996) indicate that no obvious trend in duct efficiency with magnetic activity can be seen in either Pacific or Atlantic NSS events. Hence part of the answer to the question is that there does not appear to be any significant influence of longitude on duct efficiency.

For the events under study in this paper, the $L$-shell of each duct was determined by using a second transmitter signal travelling with the same plasmaspheric path (Clilverd et al., 1996). In the case of NLK events at Faraday the second transmitter was NSS and for NSS events at Dunedin the second transmitter was NLK. In determining that the longitude of any given duct under study does not significantly influence the efficiency value, it is possible to combine the events from any single transmitter whether observed at Faraday or Dunedin. Figure 4 is such a plot. The efficiency of NLK events at both Faraday and Dunedin is shown and a trend similar to that seen in Fig. 2 noted. Events with duct exit regions $<500 \mathrm{~km}$ distant from the receiver have not been included in Fig. 4. Modelling the duct output power from such events is likely to be complicated by possible arrival bearing errors and small-scale excitation effects (Nagano et al., 1982). This present study has located several exit regions within $500 \mathrm{~km}$ of the receivers and these will be analysed in detail in a future paper.

The inclusion of events with duct exit regions $<500 \mathrm{~km}$ from the receiver was partly responsible for the masking of the trend in duct efficiency with $K_{\mathrm{p}}$ for NSS in Clilverd et al. (1996). An additional factor was

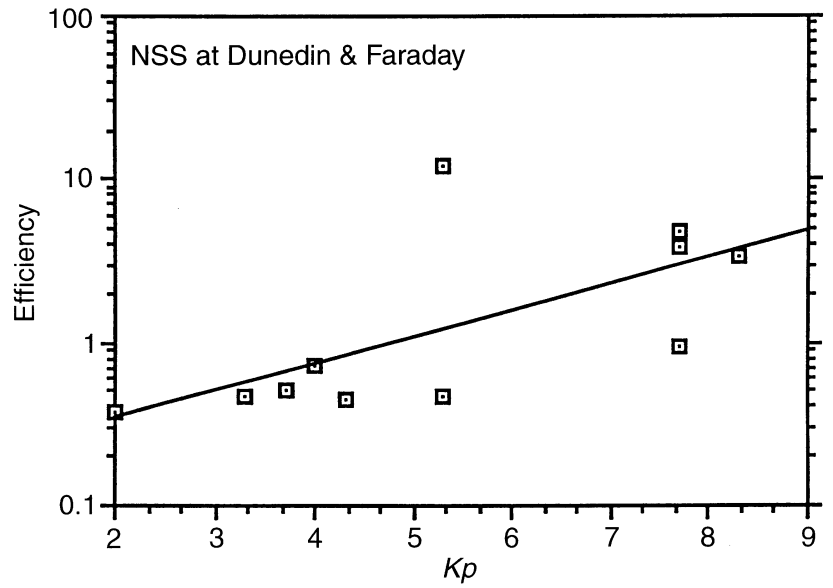

Fig. 5. As Fig. 4 but with NSS events from both Faraday and Dunedin

the small range of $K_{\mathrm{p}}$ values available. This is also true of the NSS events at Dunedin in Fig. 3. Figure 5 combines the NSS events from Faraday and Dunedin to provide a greater range of $K_{\mathrm{p}}$, but does not include the events with duct exit regions $<500 \mathrm{~km}$ from the receiver. Now the trend in efficiency with $K_{\mathrm{p}}$ is apparent. It is clear from Figs. 4 and 5 that the variation in duct efficiency with magnetic activity is similar for whistlermode signals received from both NSS and NLK.

Following the inference that there is no significant variation in duct efficiency with longitude or transmitter, it is possible to combine all events into one single plot including the events from Clilverd et al. (1996). Figure 6 is such a plot. The best-fit variation is marked by the continuous line, while the dashed lines indicate the ranges of the highest and lowest efficiency values. It can be seen that all three lines converge towards a similar value of efficiency at low $K_{\mathrm{p}}$ and diverge as $K_{\mathrm{p}}$ increases. This suggests that not only does the average duct efficiency increase with increasing $K_{\mathrm{p}}$, but the scatter about the average also increases with $K_{\mathrm{p}}$. There are

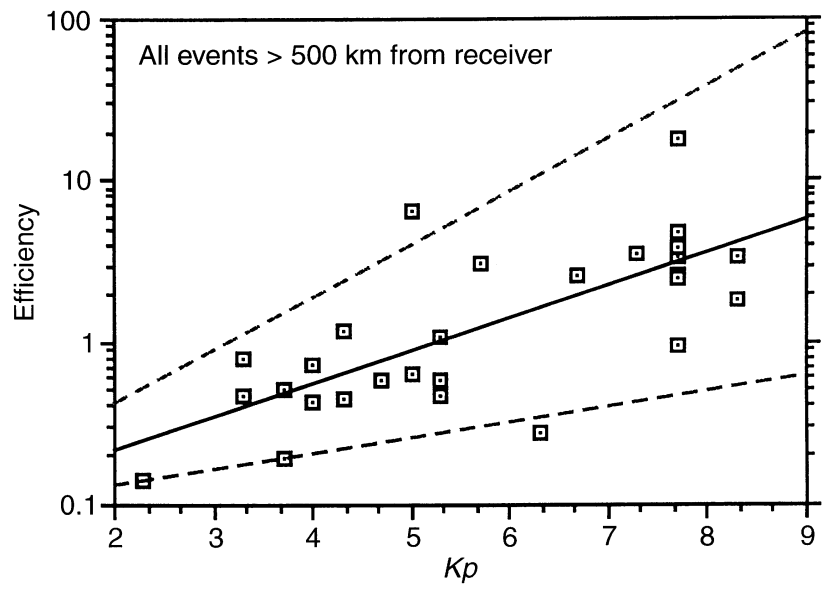

Fig. 6. A plot of the estimated efficiency of all ducts versus $K_{\mathrm{p}}$. The plot shows a logarithmic relationship between the two. The upper and lower boundaries are delineated and indicate a trend of increasing scatter with increasing $K_{\mathrm{p}}$ 
several possible reasons for this type of variation. Two such causes involve plasmaspheric wave-particle interactions and changing duct dimensions, and are discussed in the following.

Clilverd and Horne (1996) showed that the latitudinal variation of duct output power, and hence plasmaspheric gain, could be explained by wave-particle cyclotron resonance interactions in the energy range 1-40 keV. They showed that for high magnetic activity levels, positive gain, or amplification, could be expected. Duct efficiencies of 5 were found to be equivalent to plasmaspheric gain values of $13 \mathrm{~dB}$ in Clilverd et al. (1996), and it is possible for this level of amplification to
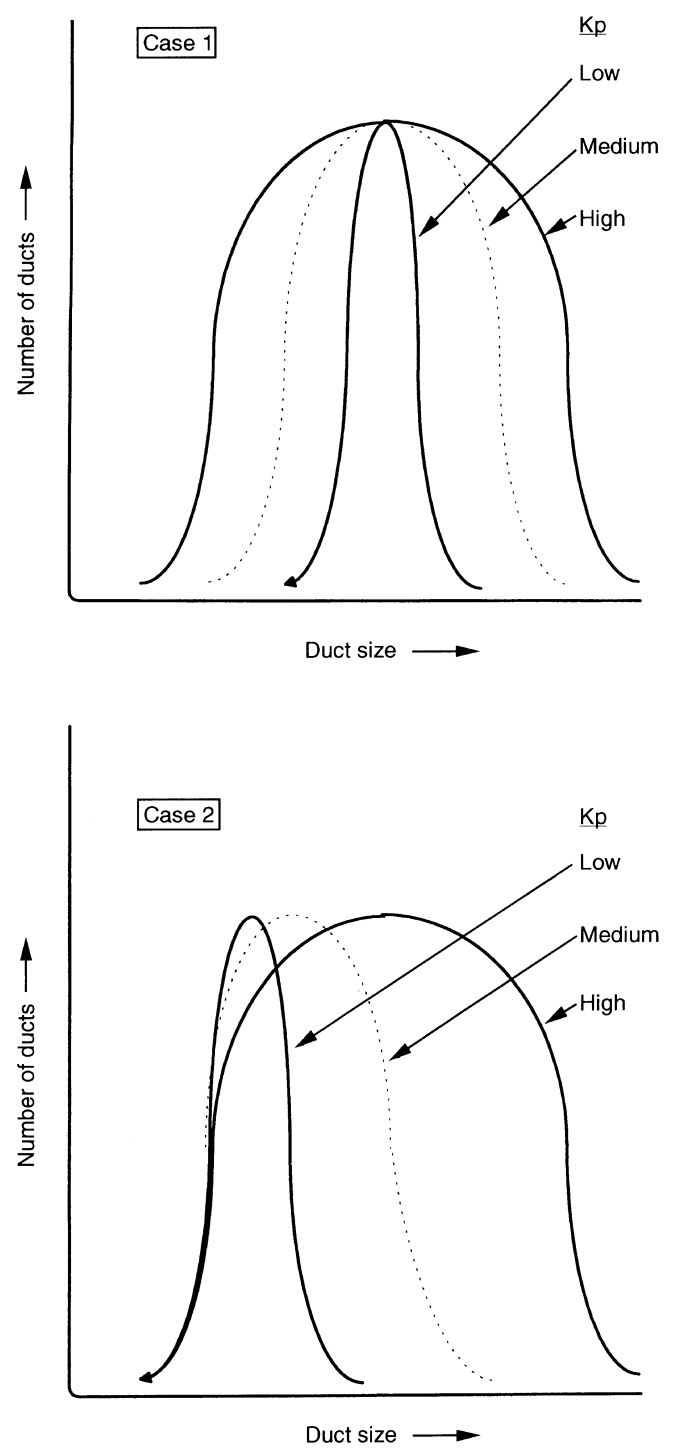

Fig. 7. A plot of possible scenarios of changing duct sizes in order to explain the variations in duct efficiency seen in Fig. 6. The top panel shows how the distribution of duct size may change with magnetic activity levels but where the average size of ducts remains unchanged. The general trend in efficiency is caused by wave-particle amplification. The lower panel shows how the distribution of duct sizes may change with magnetic activity levels in the case where no wave-particle amplification is occurring. The general trend in efficiency is caused by an increase in the average duct size with magnetic activity. See text for more details occur through increased anisotropy and energetic fluxes during increased magnetic activity. If amplification through increased anisotropy is happening for the events studied in this paper, then the scatter of values about the average in Fig. 6 could simply be caused by a range of electron energy fluxes. However, the scatter of duct efficiencies about the average may also be contributed to by a change in the distribution of duct sizes with $K_{\mathrm{p}}$. The top panel of Fig. 7 (Case 1) shows how the distribution of duct size may change with activity levels but with the average size of ducts remaining unchanged.

If no significant amplification is occurring, i.e plasmaspheric gain $=0 \mathrm{~dB}$, then the variation of duct size with activity levels must be very different. The average size of ducts must increase with $K_{\mathrm{p}}$. However, as the line marking the lower boundary of duct efficiency in Fig. 6 is nearly horizontal, the smallest size must remain constant. The lower panel of Fig. 7 (Case 2) shows how the distribution of duct sizes may change with magnetic activity levels in this case.

An argument based primarily on the size of ducts is probably more relevant to trapping through the duct base as opposed to the side of the duct. Trapping through duct bases tends to be inefficient at low altitudes, although in this study the majority of events occur during April-September when duct starting altitudes would tend to be high in the northern hemisphere (Strangeways, 1981). With higher-altitude entry, refraction of the rays by horizontal ionospheric electron density gradients becomes more significant and the variation of these gradients with magnetic activity may go someway towards explaining the output powers observed. Ionospheric gradients have been shown to be significant for ducting at times such as sunset/sunrise in previous work (Clilverd et al., 1992b). Modelling studies may be able to provide some interesting insights into this question.

Modelling studies have also shown that larger duct enhancements could be produced when latitudinal electron density gradients are increased during periods of higher $K_{\mathrm{p}}$ (R. J. Thomson, 1978; Richards and Cole 1979a, b). The higher enhancement factors can improve duct efficiency and hence reduce duct leakage, however, in this paper we assume 100\% duct efficiency and suggest that this is supported by the observations of Angerami (1970).

Clearly both the cases illustrated in Fig. 7 are conjecture and it is not possible at present to distinguish between them or any other mechanism for explaining the efficiency variation with $K_{\mathrm{p}}$. However, they do illustrate the point that determining the distribution of duct sizes with magnetic activity levels would lead to a greater understanding of the duct formation process itself.

\section{Conclusions}

A previous paper, Clilverd et al. (1996), showed that whistler-mode signals with entry regions in Pacific longitudes (typically from NLK) showed an increase in 
transmission efficiency of wave energy as magnetic activity increased. However, signals with entry regions in Atlantic longitudes (typically from NSS) did not show such a relationship.

This paper reports the results of a study of the same two longitude ranges but with the opposite transmitter providing the whistler-mode information, with $L$-values in the range 1.8-2.6. Transmissions from NLK received at Faraday show a similar increase in duct efficiency with magnetic activity levels even though the signals were propagating in Atlantic longitudes, not Pacific as reported in Clilverd et al. (1996). Hence it is apparent that no significant longitudinal influence on duct efficiency occurs.

The trend in efficiency for NSS events observed at Dunedin was confused by a limited range of magnetic activity and also duct exit regions so close to the receiver that small-scale excitation effects appeared to be occurring. These same effects were identified as influencing the data in the previous study. By combining data from both longitudes, i.e. Pacific and Atlantic, and using only ducts with exit regions that were $>500 \mathrm{~km}$ from the receiver, NSS events showed the same trend of increased duct efficiency with $K_{\mathrm{p}}$ as the NLK events. Duct efficiency increases by a factor of about 30 with $K_{\mathrm{p}}=2-8$. No significant transmitter-related variations in duct efficiency could be detected in this study.

The finding that no significant changes in duct efficiency occur with transmitter or longitude (at least in the sector $60^{\circ}-180^{\circ} \mathrm{W}$ ) allows all of the data to be combined. The average trend of duct efficiency with $K_{\mathrm{p}}$ is similar to that seen in the individual NSS and NLK events. However, with a larger sample of events it is also possible to delineate the upper and lower boundaries of the efficiency values, thus representing the scatter of values about the average. Both the duct efficiency and the scatter in the duct efficiency are observed to increase with $K_{\mathrm{p}}$ and this can be understood in terms of both duct size and the scatter in duct sizes increasing with increasing magnetic activity. Alternatively, these duct efficiency increases (and their increased scatter) could be due to plasmaspheric amplification resulting from enhanced magnetic activity increasing the range of anisotropy and particle energy fluxes.

Acknowledgements. The authors would like to thank the British Council for providing travel funding to assist the collaboration between them and also to thank J. A. Ferguson for his permission to use LWPC.

Topical Editor K.-H. Glaßmeier thanks M. Parrot and another referee for their help in evaluating this paper.

\section{References}

Allcock, G. McK., and F. A. McNeill, The reception of whistlermode signals at a point remote from the transmitter's magnetic conjugate point, J. Geophys. Res., 71, 2285, 1966.
Angerami, Whistler Duct Properties Deduced from VLF Observations Made with the Ogo 3 Satellite near the Magnetic Equator, J. Geophys. Res., 75, 6115, 1970.

Clilverd, M. A., and R. B. Horne, Ground-based evidence of latitude-dependent cyclotron absorption of whistler-mode signals originating from VLF transmitters, J. Geophys. Res., 101, 2355, 1996.

Clilverd, M. A., A. J. Smith, and N. R. Thomson, The annual variation in quiet-time plasmaspheric electron density, determined from whistler-mode group delays, Planet. Space Sci., 39, 1059, 1991.

Clilverd, M. A., N. R. Thomson, and A. J. Smith, Observation of two preferred propagation paths for whistler-mode VLF signals received at a non-conjugate location, J. Atmos. Terr. Phys., 54, 1075, 1992a.

Clilverd, M. A., A. J. Smith, and N. R. Thomson, The effects of ionospheric horizontal electron density gradients on whistlermode signals, J. Atmos, Terr, Phys., 54, 1061, 1992 b.

Clilverd, M. A., N. R. Thomson, and A. J. Smith, Ducted whistlermode signals received at two widely spaced locations, Ann. Geophysicae J, 14, 619, 1996.

Ferguson, J. A., and F. P. Snyder, Computer programs for assessment of long wavelength radio communications (Version 1.0:Full FORTRAN code user's guide, 1 April 1990). National Ocean Systems Center (NOSC), Alexandria, Virginia, USA, Technical document 1773, 1990.

Nagano, I., M. Mambo, S. Yoshizawa, I. Kimura, and H. Yamagishi, Full wave calculation for a Gaussian VLF wave injection into the ionosphere, Mem. Nat. Inst. Polar Res., 22, 46, 1982.

Richards, P. G., and K. D. Cole, Numerical solutions of the timedependent heat energy equations for the magnetosphere, Planet. Space Sci., 27, 1343, 1979a.

Richards, P. G., and K. D. Cole, A numerical investigation of the formation and evolution of magnetospheric irregularities by the interchange of magnetic flux tubes, Planet. Space Sci., 27, 1351, $1979 b$.

Saxton, J. M., and A. J. Smith, Quiet-time plasmaspheric electric fields and plasmasphere-ionosphere coupling fluxes at $L=2.5$, Planet. Space Sci., 37, 283, 1989.

Smith, A. J., VELOX: a new VLF/ELF receiver in Antarctica for the Global Geospace mission, J. Atmos. Terr. Phys., 57, 507, 1995.

Smith, A. J., and M. A. Clilverd, Magnetic storm effects on the mid-latitude plasmasphere, Planet. Space Sci., 39, 1069, 1991.

Smith, A. J., K. H. Yearby, K. Bullough, J. M. Saxton, H. J. Strangeways, and N. R. Thomson, Whistler-mode signals from VLF transmitters observed at Faraday, Antarctica, Mem. Nat. Inst. Polar Res., 48, 183, 1987.

Strangeways, H. J., Trapping of whistler-mode waves in ducts with tapered ends. J. Atmos. Terr. Phys., 43, 1071, 1981.

Strangeways, H. J., and N. R. Thomson, 24-kHz MSK Doppler receiver at Faraday Antarctica, IERE Publication, 68, 41, 1986.

Tanaka, Y., M. Nishino, and K. J. W. Lynn, On the propagation of LF whistler-mode waves deduced from conjugate measurements at low-latitudes, Planet. Space Sci., 37, 1215, 1989.

Thomson, N. R., Whistler-mode signals: spectrographic group delays, J. Geophys. Res., 86, 4795, 1981.

Thomson, N. R., Reflection of VLF radio waves from distant mountain ranges, J. Atmos. Terr. Phys., 47, 353, 1985.

Thomson, R. J., The formation and lifetime of whistler ducts, Planet. Space Sci., 26, 423, 1978.

Tsuruda, K., Penetration and reflections of VLF waves through the ionosphere: full-wave calculations with ground effect, J. Atmos. Terr. Phys., 35, 1377, 1973. 